was, and remained, high in the two cases followed by acute rheumatism, and became gradually normal within three weeks in the other two. Five more cases of untreated haemolytic streptococcal tonsillitis developed erythema nodosum at the end of Jan., 1945, when treatment with penicillin pastilles was introduced; they had been given the pastilles as soon as the rash became evident. Two more cases were admitted with a history of erythema nodosum of 1 to 2 days' duration; they also were given penicillin pastilles. In one of them acute rheumatism followed very soon. In all those instances in which penicillin pastilles were given the rash faded and disappeared in 1 to 3 days, and the erythrocyte sedimentation rate dropped from values ranging between 23 and $54 \mathrm{~mm}$. per hour to less than $10 \mathrm{~mm}$. per hour on the fifth day at the latest, with the exception of the one followed by rheumatic fever. All throat swabs became negative within 4 days. All the 11 cases of erythema nodosum $\cdot$ had a thorough clinical and radiological examination to exclude tuberculosis.

On two occasions " erythema nodosum " appeared in patients with lobar pneumonia under sulphathiazole treatment. The E.S.R. was 10 and $14 \mathrm{~mm}$. per hour. Sulphath.azole was discontinued, and the rash disappeared within 24 hours. Not a single patient suffering from haemolytic streptococcal tonsillitis and treated with penicillin pastilles developed erythema nodosum.

\section{Acute Rheumatism}

Six of our tonsillitis cases of the first group developed rheumatic fever while in hospital; two of them-as mentionedhave also had erythema nodosum. - None of the patients treated with penicillin pastilles showed any signs of acute rheumatism. From those admitted with already evident symptoms, 6 were fresh cases and 4 relapses. All but one gave a history of recent tonsillitis, and all throat swabs showed a growth of haemolytic streptococci.

The first six patients were treated with intramuscular penicillin injections. In all but one case pyrexia did not last for more than two days, and the E.S.R. returned to normal at the 14th day at the latest. The swelling remained confined to the primarily affected joints, and subsided in 3 to 10 days. Only one had a clinical course which, though mild, could not be regarded as affected by treatment. Of the patients who were admitted with already developed rheumatic symptoms, 3 fresh and 2 relapsing cases were given penicillin treatment; the rest had the customary doses of sodium salicylate. Two of the primary and one of the relapsing penicillin-treated cases showed the course described above. All the others presented the wellknown clinical picture of this disease.

The maximum amount of penicillin given was half a million units. It is noteworthy that three of those patients whose course of illness seemed to have been affected by the penicillin treatment liked the tiresome three-hourly injections immensely and begged us not to discontinue them.

\section{Comment}

The superiority of peniciliin to sulphonamides in treatment of haemolytic streptococcal infections had been sufficiently stressed by the American National Research Council (1943) and Herrel (1944). The results achieved by Plummer et al. (1945) in throat infections with systemic penicillin treatment are better than ours- "Improvement in 8 to 12 hours, fever normal in 24 hours, and all throat swabs negative in 48 hours"-but relapses and complications were frequent unless the treatment was carried through for six days. MacGregor and Long (1944) had good results with penicillin pastilles, but found the treatment of carriers disappointing. The longer duration of illness in our patients as compared with those of Plummer et al. may be considered partly counterbalanced by the absence of recurrences and complications and the cheapness and simplicity of the treatment. Our results with peritonsillar abscesses can safely be described as striking; on several occasions the abscesses "melted away."

The relatively frequent occurrence of erythema nodosum is of some theoretical interest. Though there is a tendency to minimize the importance of the "rheumatic" origin as compared with the tuberculous, experimental work has shown that streptococcal nucleoprotein can cause the typical eruptions (Collis, 1932 ; Coburn and Moore, 1936). Lymphopathia venerea and sulphonamides may also cause "erythema nodosum." It seems feasible that just as discontinuation of sulphonamides is followed by disappearance of the eruption, so sterilization of the throat with penicillin pastilles may abort or even prevent the development of erythema nodosum.

Though acute rheumatism may follow different infections (Copeman, 1944), the connexion with haemolytic streptococci is certainly common, as shown only lately for the Canadian Army (Feasby, 1944). We are unable to explain by coincidence alone the benign course of several of our cases treated with penicillin. This is in contradiction to the conclusions of Watson et al. (1944), Herrel and Kennedy (1944), and Foster et al. (1944); the last-named author believes even in a deleterious effect of penicillin. The number of cases reported by these authors seems to us too small for a definite conclusion.

\section{Summary}

Acute haemolytic streptococcal tonsillitis and peritonsillar abscess respond well to treatment with penicillin pastilles.

Erythema nodosum following haemolytic streptococcal tonsillitis may be aborted, and possibly prevented, by penicillin pastilles.

Some cases of rheurnatic fever seem to respond to systemic penicillin treatment.

I wish to thank Lieut.-Col. J. Pyle, C.O. of the hospital, for permission to publish this paper; and Sister K. Keogh, Q.A.I.M.N.S., for her valuable assistance in observation and treatment of the patients.

\section{REFERENCES}

Coburn, A. F., and Moore, L. V. (1936). J. clin. Invest., 15, 509

Collis, W. R. F. (1932). Ouart. J. Med., 25, 141 .

Copeman W. S. C (1944), Ann rheum Dis., 4, 11

Feasby, W. R. (1944). War Med., 6, 139

Foster, F. P., et al. (1944). J. Amer, med. Ass., 126, 281.

Herrel, W. E. (1944). Ibid., 124, 62 .

- and Kennedy, R. L. J. (1944). J. Pediat., 25, 505

MacGregor, A. B., and Long, D. A. (1944). British Medical Journal, 2, 686.

National Research Council Report (1943). J. Amer. med. Ass., 122, 1217.

Plummer, N., et al. (1945). Ibid., 127, 369.

Watson, R. P., et al. (1944). Ibid., 126, 274

\section{TWO UNUSUAL STRESS FRACTURES}

\section{IAN D. KITCHIN, F.R.C.S.Ed.}

AND

\section{DAVID A. RICHMOND, F.R.C.S.} Surgeon, E.M.S.

Stress fracture, as represented by spontaneous fracture of a metatarsal, usually the second, was common enough during the war of 1914-18, but stress fractures of other bones were not recognized as such at that time, and very little was heard on the subject until Roberts and Vogt, in 1939, published 12 cases of "pseudo-fracture of the tibia." Since then stress fracture - to use the most popular name-has been recognized in a variety of sites. That it is a true spontaneous fracture and not a "pseudo" was first demonstrated in one of Hartley's (1942) cases, although fracture with displacement did occur in one case of Roberts and Vogt's, but there trauma could not be altogether excluded. Now stress fractures have been reported as occurring in metatarsals, fibula, tibia, femur-shaft and neck-pubis, vertebrae, and first rib.

In two of the early series of cases published, where the bone involved was the tibia, the average age of the patients was just over 10 years. In all series those affected are almost entirely adolescent or in the early twenties and involved in strenuous exertion; though in 1940 Jackson Burrows reported a case of spontaneous fracture of the lower third of the fibula in a lady of 61 years who had been leading an energetic life. It is this almost invariable history of early age and strenuous exertion in cases of stress fracture which has prompted us to describe in detail the following two cases.

\section{Case I}

Miss C., aged 64, housekeeper. She was first seen by one of us on Oct. 6, 1944, when she complained of pain in the upper third of the right tibia of one month's duration. There was no history of injury; her work was not hard and her duties had not varied for a number of years. The pain was described as gnawing in character, and, strangely enough, was most severe at night, being 
sufficiently so to keep her awake. On Sept. 27 she had been radiographed at the request of her own doctor, but no lesion was found. Clinically the only.positive finding was slight thickening and pitting at the site of pain, and marked osteo-arthritic grating of both knees. $X$-ray examination at this stage showed the early stages of what later proved to be a typical stress fracture. Films taken at intervals revealed all the features of stress fracture, both in its incipient stage and in its progress. The nick in the cortex followed by a clear infraction, with later the typical transverse zone almost right across the shaft, was clearly demonstrated.

The second case is most interesting from the point of view of differential diagnosis, for at one stage the $x$-ray films were so suggestive of sarcoma that a biopsy was performed.

\section{Case II}

Pte. T., aged 18. After a strenuous infantry exercise the patient complained of pain in the left knee. There was no history of injury. The pain had been present for some weeks before he was sent to hospital. When seen there it was referred to the knee-joint generally, but more especially to the medial side of the lower end of the femur, where a tender bony-hard swelling could be felt. Full range of knee movement was present. Radiologically (Fig. 1)
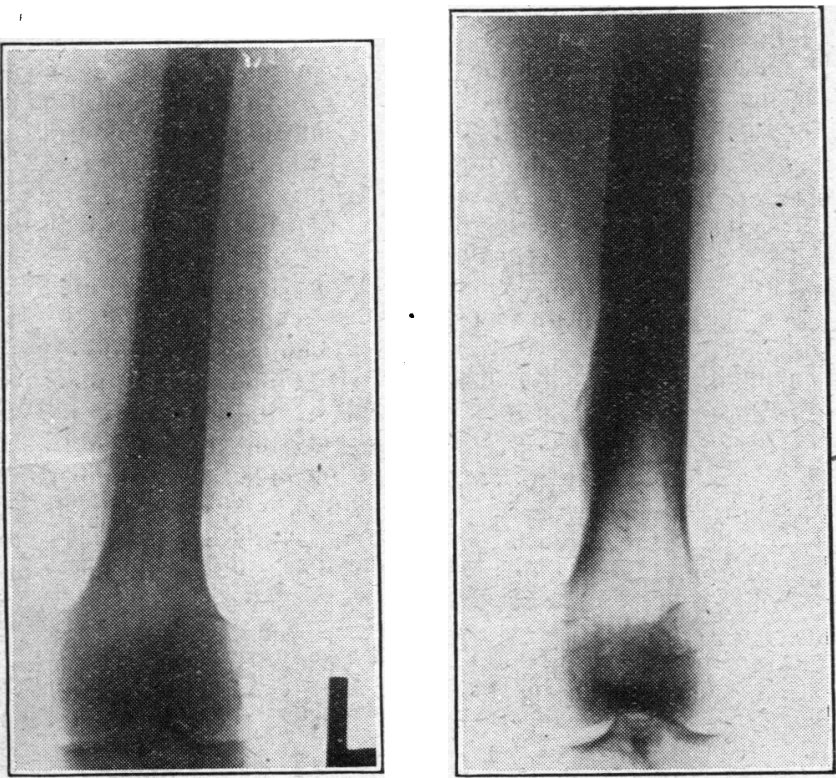

FIG. 1.-Case II. The broad-based pyramid is clearly seen and layering of the periosteum can be made out.

FIG. 2.-Case II. The layering is more clearly seen.

the swelling was seen to be due to a heaping up of poorly calcified bone in a low broad-based pyramid, and extending along the femoral shaft in both directions from its base was a thin layer of similar new bone. This layer was seen on the medial, anterior, and posterior surfaces, extending practically to mid-shaft. Underlying the pyramid was a region of endosteal new bone extending nearly halfway across the shaft. A cortical nick could be clearly seen in the negative. A tentative diagnosis of stress fracture was made at this stage. The onion-skin layering of the new bone extending along the shaft, however, gave rise to some anxiety. Control films of the opposite femur failed to show any similar changes. The Wassermann reaction was negative, and at no time was there any sign of local inflammation. Ewing's tumour and osteogenic sarcoma were considered, but it was decided to watch the progress of the swelling and take frequent control radiographs.

With rest in bed the tenderness and pain diminished, and at the end of three weeks the swelling had not increased in size. Films at this stage showed that the new bone was more densely calcified and better defined. At the end of another three weeks the clinical condition was unchanged, and a radiograph (Fig. 2) showed a further increase in density of the new bone mass, and its outline was smoother.

We now felt that the diminution of pain and tenderness, taken in conjunction with the radiological findings, indicated a healing lesion and almost confirmed our earlier diagnosis of stress fracture; but we were still uneasy about the earlier periosteal changes, and so a biopsy was performed. When the swelling was exposed (D. A. R.)-and this was done easily, there being no infiltration of the surrounding tissues - the pyramid was found to be hard, smooth, and rounded, and it easily scaled off the underlying bone, leaving a smooth normal-looking cortex. A portion of the cortex and underlying cancellous bone was removed. Macroscopically this could not be distinguished from normal bone.

The specimens were examined microscopically by Dr. J. Carr Brundret, who reported the presence of subacute and chronic osteitis compatible with the clinical diagnosis of stress fracture. There was no evidence of Ewing's tumour or sarcoma.

Still later films showed a more calcified new bone which was gradually merging into the normal cortex, and four months after the onset of symptoms the man was discharged to his unit.

\section{Comment}

Of these two cases the second is the more unusual, and both clinically and radiologically the more important. The first presents four unusual features - the relatively advanced age of the patient, the nocturnal pain, the absence of a history of strenuous exertion, and the presence of well-established osteoarthritis; but, apart from that, the behaviour of the case was that of a typical stress fracture, and the diagnosis was never in doubt. Diagnosis was much more difficult in the second case, for while the changes seen radiologically to be taking place within- the cortex were those usually associated with stress fractures, the much more widespread subperiosteal changes were very suggestive of sarcoma.

We wish to thank Dr. R. Fawcitt and Dr. J. Blair Hartley for their criticism and help with the films.

REFERENCES

Burrows, H. J. (1940). Brit. J. Surg., 28, 82.

Hartley, J. B. (1942). Ibid., 30, 9.

Roberts, S. M., and Vogt, E. C. (1939). J. Bone Jt. Surg., 21, 891.

\section{TUBERCULIN TESTING IN CHILDREN}

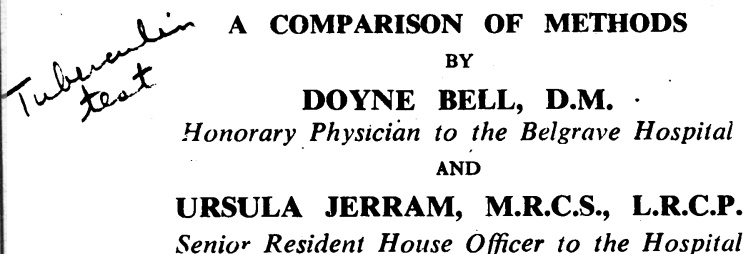

The investigation here reported has been carried out with a view to comparing the sensitivity of children to three forms of the tuberculin skin test : first, the Mantoux intradermal test ; second, the Vollmer patch test; third, the diagnostic tuberculin jelly test.

In all, 380 children were tested, of whom 200 did not react to any of the tests. It is with the remaining 180 children that we are concerned. These 180 are made up of two groups of children: first, cases in a sanatorium, diagnosed on clinical, radiological, or bacteriological grounds as cases of active tuberculosis, the lesions being pulmonary, glandular, or in the bones or joints ; second, cases attending a children's hospital that were found to be suffering from unexplained cough or glandular enlargement or showed other signs or symptoms giving rise to a suspicion of tuberculosis, or children who gave a history of contact with open tuberculosis.

Technique.-The Mantoux test was performed by the injection of $0.1 \mathrm{c.cm}$. of $1 / 10,000$ old tuberculin into the skin on the flexor aspect of the forearm, and was read 48 hours after injection. Where this reaction was negative the test was i nmediately repeated, using 1/1,000 old tuberculin and reading again after 48 hours. The Vollmer patch and the jelly tests were both applied on the back between the shoulder-blades after the skin had been cleaned with aether meth. The jelly was applied in the shape of the letter $V$, each arm of the $V$ about $1 / 2$ in. long. The jelly was immediately covered by a large patch of elastoplast, about $3 \mathrm{in}$. by 2 in., extending well beyond the area of skin covered by the jelly; in this way any skin reactions to the elastoplast could be distinguished from reactions to the jelly; in fact, no such reactions were encountered.

The patches used in all the cases here recorded were fresh and from one source. Both patch and jelly tests were read after 48 hours.

Interpretation of Tests.-A positive Vollmer patch test was recorded if the reaction was positive either to human or to bovine tuberculin, or to both. A positive Mantoux was recorded if, after 48 hours, there was a palpable wheal not less than $3 / 4 \mathrm{~cm}$. in 